\title{
Antibiotic prophylaxis in permanent pacemaker implantation: a prospective randomised trial
}

\author{
J P Mounsey, M J Griffith, M Tynan, F K Gould, A F N MacDermott, R G Gold, \\ R S Bexton
}

\author{
Departments of \\ Cardiology and \\ Microbiology, \\ Northern Regional \\ Cardiothoracic Centre \\ Freeman Hospital \\ Newcastle upon Tyne \\ J P Mounsey \\ M J Griffith \\ $M$ Tynan \\ F K Gould \\ A F N MacDermott \\ R G Gold \\ R S Bexton \\ Correspondence to: \\ Dr J P Mounsey, \\ Department of Internal \\ Cardiology, University of \\ Virginia Medical Center, \\ Box 438-29, Charlottesville, \\ Virginia 22908, USA. \\ Accepted for publication \\ 21 April 1994
}

long term steroid treatment), although there was a trend in this direction.

Conclusions-Antibiotic prophylaxis significantly reduced the incidence of infective complications requiring a repeat operation after permanent pacemaker implantation. It is suggested that antibiotics should be used routinely.

(Br Heart f 1994;72:339-343)

Pacemaker pocket infection remains a potentially serious complication after permanent pacemaker implantation. Many operators routinely use antibiotic prophylaxis to reduce the incidence of this complication, but the trial evidence that this strategy is beneficial is not convincing. The two largest trials to date ${ }^{12}$ have conflicting conclusions. Muers et $a l^{1}$ showed a small benefit of antibiotic prophylaxis in reducing pacemaker pocket and wound sepsis, whereas Ramsdale $e t a^{2}$ saw no such benefit.

With these conflicting studies in mind, we elected to perform a large prospective randomised trial of antibiotic prophylaxis. We hoped to establish firstly whether the incidence of serious infection, which we defined as infection requiring a repeat operation, was reduced. These serious infections have been reported to occur in up to $5 \%$ of implants. ${ }^{3}$ They are unambiguous as an endpoint and their prevention should be the main goal of antibiotic prophylaxis. The secondary purpose of the trial was to identify patients at high risk of infection in whom antibiotic prophylaxis may be most efficacious, if the trial did not produce a statistically significant result in favour of the use of antibiotic prophylaxis.

\section{Methods}

PATIENTS

All adult patients (older than 18 years) who underwent elective implantation of a new permanent pacing system at the Northern Region Cardiothoracic Centre, Freeman Hospital, Newcastle upon Tyne, between 1 October 1991 and 28 February 1993 were eligible for inclusion in the trial. The trial was approved by the Northern Regional Health Authority ethical committee. Patients undergoing pulse generator or electrode changes were not studied. Patients with overt sepsis in whom the operator thought antibiotics were clinically indicated were excluded. Also excluded were 
patients who refused consent and those whom it was inappropriate to approach for informed consent because of, for example, dementia. Those patients who refused consent and those who were not approached received antibiotics if it was the operator's usual practice to use them, and the antibiotic regimen was, where given, identical to the trial regimen.

Patients who gave informed consent were randomly allocated to receive or not receive antibiotic prophylaxis immediately before the operation. The antibiotic regimen was flucloxacillin $1 \mathrm{~g}$ intravenously immediately before surgery, followed by $500 \mathrm{mg}$ by mouth every six hours for $\mathbf{4 8}$ hours. Patients allergic to penicillin received clindamycin $600 \mathrm{mg}$ intravenously immediately before surgery, followed by $300 \mathrm{mg}$ by mouth every six hours for 48 hours.

\section{OPERATION}

All implantations were performed under local anaesthesia after premedication with diazepam by mouth. All procedures were carried out under full operating theatre conditions. Standard operating packs were used. Hand cleansing was with prepacked sponges soaked either in chlorhexidine or povidone iodine. Skin preparation at the time of the operation was with $10 \%$ povidone iodine solution or $0.5 \%$ alcoholic chlorhexidine.

Standard transvenous electrodes were introduced either via the cephalic vein, the subclavian vein, or occasionally via the internal jugular vein. Electrodes were secured using either silk or absorbable (vycryl, Ethicon) sutures. Subfascial pockets were fashioned by blunt dissection and standard pulse generators were used. Wound closure was with interrupted or continuous absorbable sutures to the subcutaneous tissues. Some patients also received a continuous subcuticular suture using an absorbable suture; in others, final skin closure was with Steristrips. All wounds were dressed in the theatre using an adhesive dressing.

Patients were normally discharged from hospital on the first postoperative day after technical checks, a chest radiograph, and wound inspection. Routine technical follow up was at four to six weeks after discharge and every six to 12 months thereafter. The

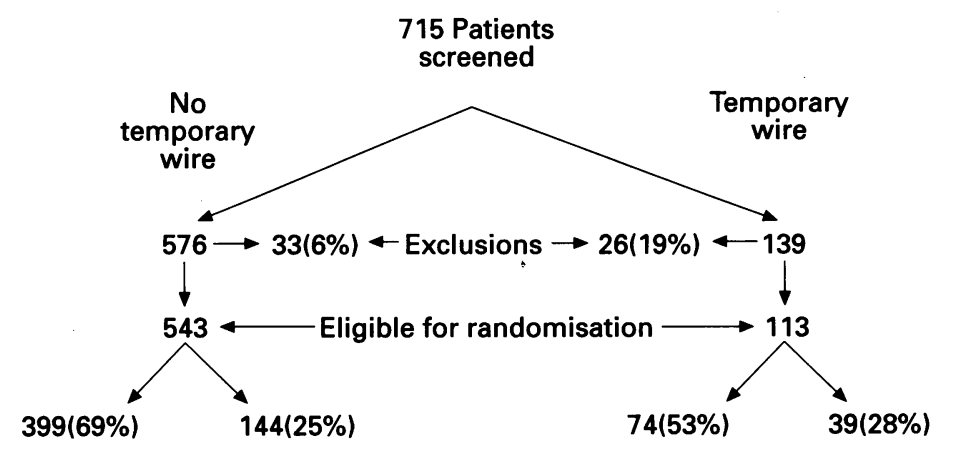

Randomised Non-randomised

Randomised Non-randomised patients were not routinely followed up in the cardiac clinic.

\section{DEFINITION OF INFECTION}

The endpoint of the trial was a repeat opera- $\frac{\text { T }}{T}$ tion for an infective complication. All pace- $\frac{T}{\Phi}$ maker complications with the potential to $\frac{\Omega}{7}$ require a repeat operation were referred back $c$. to the Freeman Hospital for assessment and $\underset{\vec{D}}{\overrightarrow{2}}$ treatment. Patients with superficial wound $\frac{9}{9}$ infections which required only local treatment or antibiotics by mouth were not deemed to have an infective complication in the analysis of this study.

A repeat operation was performed either for septicaemia, pocket abscess, or erosion of the $\vec{\circ}$ pulse generator or electrode through the skin. In patients without systemic infection the pulse $\stackrel{\omega}{S}$ generator was, where technically feasible, cleaned with alcoholic betadine and resited at a $\underset{N}{N}$ single operation. In other patients the infected system was explanted with, if necessary, connection of the electrode to an external pulse

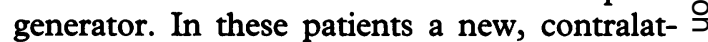
eral pacing system was implanted at a later $\overrightarrow{0}$ date. All repeat operations were performed under general anaesthesia with antibiotic cover $\frac{0}{0}$ guided, where available, by microbiological $\stackrel{\mathbb{Q}}{-}$ culture results. We have described the proce- $\vec{\theta}$ dure and outcome for primary resiting of $\$$ eroded pulse generators elsewhere. ${ }^{4}$

\section{DATA ANALYSIS}

Student's $t$ test, Fisher's exact test, and the $\chi^{2}$ test with, where appropriate, Yates's correc- $\stackrel{\mathbb{D}}{\unrhd}$ tion were used for statistical analysis. $\overrightarrow{\vec{A}}$ Significance was assumed to be $\mathbf{P}<0.05$.

\section{Results}

\section{PATIENT COHORT}

The figure shows a breakdown of the patient cohort. A total of 715 patients was screened for inclusion in the trial. One hundred and $\delta$ thirty nine $(19.4 \%)$ of these had temporary pacing electrodes in situ; $576(80.6 \%)$ did 을 not. In the group without temporary elec- $D$ trodes, $33(6 \%)$ were excluded, $399(69 \cdot 2 \%)$ 을 were entered into the randomised trial, and $N$ $144(25 \%)$ were not randomised. Among patients with temporary electrodes, $26(19 \%)$ N were excluded, 74 (53\%) were entered into the randomised trial, and $39(28 \%)$ were not randomised. Thus a total of 473 patients were randomised; $224(47 \%)$ of these received $\stackrel{\oplus}{\rightarrow}$ antibiotics and 249 (53\%) did not. Data for the primary endpoint-that is, pacemaker

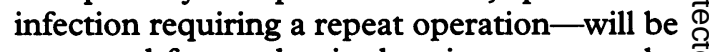
presented for randomised patients separately. $\stackrel{\mathbb{D}}{\mathbb{2}}$

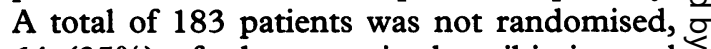
$64(35 \%)$ of whom received antibiotics and $119(65 \%)$ did not. Thirteen of these patients (7\%) were not approached for consent because of dementia or other psychiatric illness; the remainder did not consent. These non-randomised patients, who received antibiotic prophylaxis or not according to the operator's usual practice, will be included in the analysis of predictors of pacemaker infection. Flucloxacillin was the antibiotic used in 
$89 \%$ of patients. The remaining $11 \%$ received clindamycin.

This report is based on data analysis up to 1 November 1993 so the follow up period ranges from nine to 26 months (mean (SD) 19 (five) months, identical for treated and untreated groups).

\section{COMPARISON OF TREATED AND UNTREATED GROUPS}

Table 1 shows the baseline characteristics of the patient cohort, including randomised and non-randomised patients. There was no significant difference in baseline characteristics between randomised and non-randomised patients. There was no significant difference between the antibiotic and non-antibiotic groups of patients with respect to age, sex, pacing mode, procedure time, or perioperative blood loss (calculated from the weight of blood saturated swabs). A similar proportion of pacemakers in each group was implanted by junior operators with 100 cases or less previous pacing experience. There was no difference in the proportion of patients in each group who had one or more preexisting disorders likely to predispose to infection-for example, diabetes, corticosteroid treatment, malignancy, or a recent operation.

Twenty eight patients $(4.3 \%)$ had a repeat operation for non-infective complications. This rate was similar in the treated and untreated groups (table 1). Twenty patients $(3.0 \%)$ had one or both electrodes repositioned less than 14 days after the initial operation and six patients $(0.9 \%)$ had electrodes repositioned or replaced 14 days to six months after implantation. Two patients $(0 \cdot 3 \%)$ required early pulse generator changes because of generator failure (six days and 49 days after implantation). All patients who received antibiotic prophylaxis at implanta-

Table 1 Comparison of patient characteristics and operative details for treated and untreated groups

\begin{tabular}{llll}
\hline Patient characteristic & $A B+(n=288)^{*}$ & $A B-(N=368)^{*}$ & $P$ Value \\
\hline Mean (SD) age (years) & $74 \cdot 3(11 \cdot 8)$ & $74 \cdot 2(12 \cdot 6)$ & $1 \cdot 0$ \\
Sex (\% male) & 55 & 55 & $1 \cdot 0$ \\
Preoperative high risk & 19 & 14 & $0 \cdot 1$ \\
Pacing mode & 9 & 9 & \\
$\quad$ Single chamber atrial & 50 & 57 & $0 \cdot 2$ \\
$\quad$ Single chamber ventricular & 41 & 34 & $0 \cdot 8$ \\
$\quad$ Dual chamber & 30 & 31 & 0.3 \\
$\quad$ (<100 patients) & $55(24)$ & $53(27)$ & 0.4 \\
Mean (SD) Duration of operation & (minutes) & $28(36)$ & 0.9 \\
Mean (SD) Blood loss (ml) & $31(41)$ & 4 & \\
Repeat operation, non-infective & 4 & & \\
$\quad$ complication & & &
\end{tabular}

* The percentage of patients with the designated characteristic is shown unless otherwise stated.

Table 2 Outcome: infection rates

\begin{tabular}{llll}
\hline Patient group & $A B+{ }^{*}$ & $A B-^{*}$ & $P$ Value \\
\hline Randomised patients & $0 / 224(0 \%)$ & $9 / 249(4 \%)$ & 0.003 \\
Total cohort & $1 / 288(0 \cdot 3 \%)$ & $12 / 368(3 \%)$ & 0.006 \\
Patients with no temporary wire & $0 / 234(0 \%)$ & $9 / 300(3 \%)$ & 0.012 \\
Patients with temporary wire & $1 / 53(2 \%)$ & $3 / 60(5 \%)$ & 0.6 \\
\hline
\end{tabular}

* Patients receiving antibiotics are designated $\mathrm{AB}+$ and those not receiving antibiotics $\mathrm{AB}$-. tion had antibiotics either continued or prescribed again at the time of the repeat operation. Four patients who did not receive prophylaxis at implantation received antibiotics at the time of the repeat operation. In each of these early repositioning of a displaced electrode was carried out.

\section{PACEMAKER INFECTIONS}

Table 2 shows observed infection rates for antibiotic and non-antibiotic groups. Among the randomised patients there was a total of nine infections requiring a repeat operation, two of which occurred in patients with temporary electrodes. All infections were in the nonantibiotic group and this represents a statistically significant benefit for antibiotic prophylaxis $(P=0.003)$.

In the total patient cohort, including nonrandomised patients, there were 13 infections, all but one in the non-antibiotic group. This difference was also statistically significant. Nine of these infections occurred in patients without temporary electrodes, all in the nonantibiotic group, and this difference was also statistically significant. Among patients with temporary electrodes antibiotic prophylaxis did not confer a benefit. There were four infections in this group, which represents an overall infection rate of $3.5 \%$. One of the patients had received antibiotics and the difference between the antibiotic and nonantibiotic groups was not statistically significant.

\section{MODES OF PRESENTATION OF INFECTED}

\section{PACEMAKERS}

Table 3 gives details of the patients who became clinically infected. The most common mode of presentation of pacemaker infection was erosion of either the pulse generator or the pacing electrode. This occurred in nine patients 171 (77) days after implantation (range 97-346 days). Bacterial pathogens were identified in two patients (Staphyloccus aureus and Enterococcus faecalis), skin or mixed faecal flora in five patients, and there was no bacterial growth in two patients.

Three patients presented with septicaemia. In each instance the patient presented within 10 days of the operation and the organism responsible was Staphylococcus aureus. One patient presented with a closed pocket abscess. This patient also presented early and the organism was Staphylococcus epidermidis. None of the patients died as a result of pacemaker infection.

\section{PREDICTORS OF PACEMAKER INFECTION}

Table 4 gives the factors which were of significance in the prediction of pacemaker infection. A significant excess of pacemakers which became infected were implanted by inexperienced operators who had previously performed less than 100 pacemaker implantations. Conversely, no infection occurred in patients where the operator had previously performed more than 500 operations. The mean operation time was significantly prolonged in patients who developed infections. 
Table 3 Infections after pacemaker implantation

\begin{tabular}{|c|c|c|c|c|c|c|c|c|c|c|c|}
\hline \multirow[b]{2}{*}{$\begin{array}{l}\text { Patient } \\
\text { No }\end{array}$} & \multirow[b]{2}{*}{$\begin{array}{l}\text { Age } \\
\text { (years) }\end{array}$} & \multirow[b]{2}{*}{ Mode } & \multicolumn{5}{|c|}{ Implantation } & \multicolumn{4}{|c|}{ Repeat operation } \\
\hline & & & $A B^{\star}$ & $\begin{array}{l}\text { Experience } \\
\text { of operator }\end{array}$ & $\begin{array}{l}\text { Operation } \\
\text { time (min) }\end{array}$ & $\begin{array}{l}\text { Blood loss } \\
(\mathrm{ml})\end{array}$ & Lead redo & $\begin{array}{l}\text { Interval } \\
\text { (days) }\end{array}$ & Presentation & Swab culture & Treatment \\
\hline \multicolumn{12}{|c|}{ Patients without temporary electrodes } \\
\hline 1 & 75 & AAI & - & I & 60 & 15 & $\mathbf{N}$ & 346 & Erosion & $\begin{array}{l}\text { Faecal flora } \\
E \text { coli }\end{array}$ & $\begin{array}{l}\text { Reimplantation } \times 2 \text {, } \\
\text { ciprofloxacin, } \\
\text { good result }\end{array}$ \\
\hline 2 & 72 & DDD & - & I & 137 & 20 & $\mathbf{N}$ & 97 & Erosion & $S$ aureus & $\begin{array}{l}\text { Reimplantation } \times 2 \text {, } \\
\text { flucloxacillin, } \\
\text { chronic wound sinus }\end{array}$ \\
\hline 3 & 79 & VVI & - & I & 115 & 30 & $\mathbf{N}$ & 198 & Erosion & Skin flora & $\begin{array}{l}\text { Reimplantation, } \\
\text { flucloxacillin } \\
\text { good result }\end{array}$ \\
\hline 4 & 92 & VVI & - & $\mathrm{E}$ & 80 & 45 & $\mathbf{Y}$ & 115 & Erosion & Skin flora & $\begin{array}{l}\text { Reimplantation, } \\
\text { flucloxacillin, } \\
\text { good result }\end{array}$ \\
\hline 5 & 79 & DDD & - & I & 120 & 30 & $\mathbf{Y}$ & 116 & Erosion & No growth & $\begin{array}{l}\text { Reimplantation, } \\
\text { flucloxacilin, } \\
\text { good result }\end{array}$ \\
\hline 6 & 82 & VVI & - & $\mathrm{E}$ & 38 & 20 & $\mathbf{N}$ & 106 & Erosion & Skin flora & $\begin{array}{l}\text { Reimplantation, } \\
\text { flucloxacillin, } \\
\text { good result }\end{array}$ \\
\hline 7 & 86 & VVI & - & I & 55 & 25 & $\mathbf{N}$ & 135 & Erosion & No growth & $\begin{array}{l}\text { Reimplantation, } \\
\text { flucloxacillin, } \\
\text { good result }\end{array}$ \\
\hline 8 & 66 & AAI & - & E & 101 & 135 & $\mathbf{Y}$ & 8 & Septicaemia & $S$ aureus & $\begin{array}{l}\text { Intravenous } \\
\text { flucloxacillin, } \\
\text { pacemaker explanted, } \\
\text { contralateral new } \\
\text { system, good result }\end{array}$ \\
\hline 9 & 70 & DDD & - & $\mathbf{E}$ & 65 & 15 & $\mathbf{N}$ & 5 & Septicaemia & $S$ aureus & $\begin{array}{l}\text { Intravenous } \\
\text { flucloxacillin, } \\
\text { pacemaker explanted, } \\
\text { contralateral new, } \\
\text { system, good result }\end{array}$ \\
\hline \multicolumn{12}{|c|}{ Patients with temporary electrodes } \\
\hline 10 & 78 & VVI & - & I & 70 & 5 & $\mathbf{N}$ & 231 & Erosion & E faecalis & $\begin{array}{l}\text { Reimplantation, } \\
\text { explanted } 29 \text { days later } \\
\text { contralateral } \\
\text { new system } \\
\text { good result }\end{array}$ \\
\hline 11 & 56 & AAI & - & I & 40 & 5 & $\mathbf{N}$ & 199 & Erosion & Skin flora & $\begin{array}{l}\text { Reimplantation, } \\
\text { flucloxacillin, } \\
\text { good result }\end{array}$ \\
\hline 12 & 65 & DDD & + & I & 76 & 25 & $\mathbf{Y}$ & 16 & Pocket abscess & $S$ epidermidis & $\begin{array}{l}\text { Intravenous } \\
\text { flucloxacillin } \\
\text { pacemaker explanted, } \\
\text { contralateral new } \\
\text { system, good result }\end{array}$ \\
\hline 13 & 60 & DDD & - & $\mathbf{E}$ & 78 & 50 & $\mathbf{N}$ & 108 & Septicaemia & $S$ aureus & $\begin{array}{l}\text { Intravenous } \\
\text { flucloxacillin, } \\
\text { pacemaker explanted, } \\
\text { contralateral new } \\
\text { system, good result }\end{array}$ \\
\hline
\end{tabular}

Those patients who had a repeat operation for non-infective complications had a significantly higher infection rate. Infection was not significantly more common in patients identified preoperatively as being at high risk of infection, though there was a trend in this direction. There was no difference between infected and non-infected groups for age, sex, or perioperative blood loss. Dual chamber pacemakers were no more likely to become infected than single chamber pacemakers.

\section{Discussion}

In this large prospective randomised trial we have shown a highly significant benefit for antibiotic prophylaxis in preventing those

Table 4 Predictors of pacemaker infection. Values are percentage of patients unless stated otherwise.

\begin{tabular}{llll}
\hline & $\begin{array}{l}\text { Infection } \\
(n=13)\end{array}$ & $\begin{array}{l}\text { No infection } \\
(n=643)\end{array}$ & $P$ Value \\
\hline $\begin{array}{l}\text { Inexperienced operator } \\
\text { (less than 100 previous cases) }\end{array}$ & 61.5 & 29.8 & 0.03 \\
$\begin{array}{l}\text { Mean (SD) operation time } \\
\text { (minutes skin-skin) }\end{array}$ & $76(29)$ & $54(25)$ & 0.003 \\
$\begin{array}{l}\text { Repeat operation } \\
\text { (non-infective complication) }\end{array}$ & 30.8 & 3.7 & 0.001 \\
$\begin{array}{l}\text { Preoperative high risk } \\
\text { nation }\end{array}$ & 30.8 & 15.8 & 0.24 \\
\hline
\end{tabular}

infective complications of permanent pacemaker implantation which require a repeat operation. This finding contrasts with all previous prospective trials of antibiotic prophylaxis, none of which showed such a large benefit of antibiotic treatment.

Two large trials showed no significant benefit for antibiotics. Ramsdale et $a l^{2}$ reported an overall infection rate of $21 / 530$ patients (3.9\%), of whom eight had received antibiotics and only three $(0.6 \%)$ required an operation (two of these received antibiotics). Bluhm et $a l^{5}$ observed no infection in 106 patients randomised to receive antibiotics or placebo. In contrast, two large trials have shown a significant benefit for antibiotic prophylaxis. Muers et $a l^{1}$ reported an overall infection rate of $9 / 431$ patients $(2 \cdot 1 \%)$, only two of whom received antibiotics. The mode of presentation and subsequent clinical course of the infected patients was not reported. In another, earlier trial from Bluhm's group ${ }^{3}$ the infection rate was $8 / 100$; one patient had received antibiotics and five required a repeat operation.

The two trials of antibiotic prophylaxis which showed no benefit had low overall rates of serious infection. The British Pacing and 
Electrophysiology Group have reported a United Kingdom national average pacemaker infection rate of $1.7 \%^{6}$ (range up to $5 \%$ ). These data do not indicate the use of antibiotic prophylaxis or specify the seriousness of the infection. As most units under report infection, however, it is most likely to be an underestimate of the true incidence of serious infection. The British Pacing and Electrophysiology Group infection rate is in accord with our result (overall infection rate $1.9 \%$ 13/669 patients) and with Muers et al. ${ }^{1}$ In contrast, Ramsdale et $a l^{2}$ report a serious infection rate of only $0.6 \%$. This low rate may have occurred by chance, but there are two major differences between their practice and ours which may explain the discrepancy.

Firstly, the patients of Ramsdale et $a^{2}$ stayed in hospital longer (three days compared with one day) and were followed up more often than ours (four times in the first year compared with two). It is possible that careful surveillance and antibiotic treatment of wound infections may have resulted in the secondary prevention of serious infection in that trial. We have no data on the incidence of superficial wound infection or of antibiotics prescribed out of hospital, and so cannot speculate whether any serious infections were aborted by early antibiotic treatment in our patient cohort.

Secondly, there was a high incidence of late pulse generator erosion in our series (9/13 infections were erosions), whereas Ramsdale et $a l^{2}$ observed none. This striking difference may have been caused by the use of a topical antibiotic spray into the generator pocket in all patients by Ramsdale et $a .^{2}$ We prospectively defined erosions as infections for the purposes of this trial because they were a cause for a late repeat operation, possibly of infective origin. ${ }^{7}$ In the event, only seven of nine erosions were overtly infected; the remaining two were microbiologically sterile. It has been argued that sterile erosions may be the result of mechanical factors alone rather than an infective process. In support of this we have previously shown that pulse generator repeat implantation is most often successful when erosions are sterile. ${ }^{4}$ That two sterile erosions occurred in the non-antibiotic group in this trial may be random chance or it may be that all erosions require an underlying infective process to initiate them. Interestingly, to date there have been no erosions in the antibiotic group in our series.

Inexperience of the operators may have contributed to the infection rate in our series. We prospectively defined a learning curve of 100 cases and, by this definition, approximately one third of pacemakers were implanted by inexperienced operators. A significant excess of infections occurred in this group of patients. In Ramsdale et al's study ${ }^{2}$ two out of five operators were in training (the number of cases previous experience was not specified); Muers et al ${ }^{1}$ do not report the proportion of operators in training, though it is probable that some of the operators in their series were, by our definition, in training.
In our series, the duration of the operation and repeat operation for non-infective complications were significantly associated with infection. None of the previous prospective trials specifically addressed either of these factors, though it seems logical that the time the wound was open and reopening the wound predispose to infection. Morgan et $a l^{8}$ noted that a repeat operation predisposed to septicaemia in patients with permanent pacemakers. There was a trend towards a higher infection rate in patients identified preoperatively as being at high risk of infection. This did not reach statistical significance, which is in accord with the data of Muers et al. ${ }^{1}$

Antibiotic prophylaxis was not beneficial in the subgroup of patients with temporary pacing electrodes in situ. This subgroup analysis was prospectively defined and, given the known high rate of infection of temporary electrodes, ${ }^{9}$ the absence of benefit is surprising. A relatively small number of patients with temporary electrodes were randomised and exclusions for overt sepsis were common in this series. For these reasons we are not confident that antibiotic prophylaxis is not beneficial in these patients and we would advocate its use on the basis of the highly significant result for the whole cohort. A large trial focused on patients with temporary electrodes would be of interest.

In conclusion, antibiotic prophylaxis significantly reduces the incidence of serious infective complications requiring a repeat operation after permament pacemaker implantation. Permanent pacemaker infections occur most commonly when the operation time is prolonged, the operator is inexperienced, and after a repeat operation for electrode displacement. We suggest that antibiotic prophylaxis (guided by the sensitivity of local bacterial flora) is used routinely in permanent pacemaker implantation.

We thank Dr D Appleton for assistance with the statistical analyses.

1 Muers MF, Arnold AG, Sleight P. Prophylactic antibiotics for cardiac pacemaker implantation: a prospective trial. Br Heart f 1 981;46:539-44.

2 Ramsdale DR, Charles RG, Rowlands DB, Singh S, Gautam PC, Faragher EB. Antibiotic prophylaxis for pacemaker implantation: a prospective randomized trial. Pace Clin Electrophysiol 1984;7:844-9.

3 Bluhm G, Jacobson B, Julander I, Levander-Lindgren M, Olin C. Antibiotic prophylaxis in permanent pacemaker Olin C. Antibiotic prophylaxis in permanent pacemaker
surgery-a prospective study. Scand $\mathcal{F}$ Thor Cardiovasc surgery-a prospective

4 Griffith MJ, Mounsey JP, Bexton RS, Holden MP. Mechanical, but not infective, pacemaker erosion may Mechanical, but not infective, pacemaker erosion may be successfully managed by re-

5 Bluhm G, Norlander R, Ransjo U. Antibiotic prophylaxis in pacemaker surgery: a prospective double blind trial with systemic administration of antibiotic versus placebo at implantation of cardiac pacemakers. Pace Clin Electrophysiol 1986;9:720-6.

6 British Pacing and Electrophysiology Group. Data Bulletin No 2: June 1993

7 Wohl B, Peters RW, Carliner N, et al. Late unheralded pacemaker pocket infection due to staphylococcus epidermidis: a new clinical entity. Pace Clin Electrophysio 1982;5:190-5.

8 Morgan G, Ginks W, Siddons H, Leatham A. Septicaemia in patients with an endocardial pacemaker. $\mathrm{Am} \mathcal{F}$ Cardiol 1979;44:221-4.

9 Lumina FJ, Rios JC. Temporary transvenous pacemaker therapy: an analysis of complications. Chest 1973;64: 